\title{
Possible Anti-Anhedonic Effect of Valproate in Mice Exposed to Chronic Mild Stress model
}

\section{Sahar Mohamed Kamal Shams El-Dine*}

Associate Professor, Department of Pharmacology, Ain Shams University, Egypt

Epilepsy is one of the most common neurological disorders characterized by recurring excessive neuronal discharge, exhibited by transient episodes of motor, sensory, or psychic dysfunction, with or without unconsciousness or convulsive movements. In addition epilepsy may be associated with neuro-degeneration presumably due to abnormal lipid per oxidation $[1,2]$. On the other hand, co-morbid depression is common in patients with epilepsy. A review of available studies [3] suggested a high prevalence of mood (affective) disorders especially major depression ( $8 \%-48 \%)$ followed by anxiety $(5 \%-32 \%)$ in patients with epilepsy.

Can the antiepileptic drug, sodium valproate induce beneficial effects on reduction in sucrose consumption and immobility in forced swimming test of stressed anhedonic albino mice. Additionally, can it has the ability to increase the activity of important anti-oxidant enzymes in hippocampus of these mice that would help in stopping the oxidative stress related to mood disorders.

Actually, these effects could have a contributing role in control of convulsions in stressed mice according to literature [4].

Accordingly, these questions need an evaluation of sucrose consumption and duration of immobility after exposure to CMSmodel for 6 weeks and forced swimming test respectively in mice treated with the anti-epileptic drug sodium valproate (administered in the last 3 weeks of the model) and compare the results with that obtained from stressed untreated albino mice.

Besides the above measured parameters, there is a strong need to measure the activities of the selected antioxidant enzymes catalase and glutathione peroxidase enzymes in hippocampus after 3 -weeks of administration of the tested drug to the tested mice $[5,6]$.

However, valproate exerted an inhibitory effect on DA-induced hyperactivity similar to that produced by GABA. GABA plays an important role in depressed mood as its reduction in CSF was reported in depressed patients and elevated when these patients were treated with selective serotonin reuptake inhibitors. These findings may suggest a possible beneficial role of valproate in improving depressed mood $[7,8]$. However, in earlier studies, valproate was injected into the nucleus accumbens and its effect on GABAergic enzymes was controversial [9]. These results open the way to further investigations to reach a proper and well-defined conclusion.

\section{References}

1. Turkdogan D, Toplan S, Karakoc $Y$ (2002) Lipid peroxidation and antioxidative enzyme activities in childhood epilepsy. J Child Neurol 17: 673-676.

2. Hamed SA, Abdellah MM (2004) Trace elements and electrolytes homeostasis and their relation to antioxidant enzyme activity in brain hyperexcitability of epileptic patients. J Pharmacol Sci 96: 349-359.

3. Hermann BP, Seidenberg M, Bell B, Woodard A, Rutecki P, et al. (2000) Comorbid psychiatric symptoms in temporal lobe epilepsy: association with chronicity of epilepsy and impact on quality of life. Epilepsy Behav 1: 184-190.

4. Deransart C, Riban V, Lê B, Marescaux C, Depaulis A (2000) Dopamine in the striatum modulates seizures in a genetic model of absence epilepsy in the rat. Neuroscience 100: 335-344.

5. Gutteridge JM, Quinlan GJ (1983) Malondialdehyde formation from lipid peroxides in the thiobarbituric acid test: the role of lipid radicals, iron salts, and metal chelators. J Appl Biochem 5: 293-299.

6. Montgomery SA (2005) Antidepressants and seizures: emphasis on newe agents and clinical implications. Int J Clin Pract 59: 1435-1440.

7. Simon D, Penry JK (1975) Sodium di-N-propylacetate (DPA) in the treatment of epilepsy. A review. Epilepsia 16: 549-573.

8. van der Laan JW, de Boer T, Bruinvels J (1979) Di-n-propylacetate and GABA degradation. Preferential inhibition of succinic semialdehyde dehydrogenase and indirect inhibition of GABA-transaminase. J Neurochem 32: 1769-1780.

9. Pinder RM, Brogden RN, Speight TM, Avery GS (1977) Sodium valproate: a review of its pharmacological properties and therapeutic efficacy in epilepsy. Drugs 13: 81-123.
*Corresponding author: Sahar Mohamed Kamal Shams El-Dine, Faculty of Medicine, Associate Professor, Department of Pharmacology, Ain Shams University, Egypt, E-mail: saharkamal2003@hotmail.com

Received July 16, 2013; Accepted July 16, 2013; Published July 18, 2013

Citation: El-Dine SMKS (2013) Possible Anti-Anhedonic Effect of Valproate in Mice Exposed to Chronic Mild Stress model. J Neurol Disord 1: e104. doi:10.4172/2329 $6895.1000 \mathrm{e} 104$

Copyright: @ 2013 El-Dine SMKS. This is an open-access article distributed under the terms of the Creative Commons Attribution License, which permits unrestricted use, distribution, and reproduction in any medium, provided the original author and source are credited. 